\title{
Medical management of abdominal hydatid cyst in a teaching hospital in Eastern Libya: treatment and outcome in 16 cases, 2004-2010
}

\author{
F.M. Makael Bohtera' and M. Patro
}

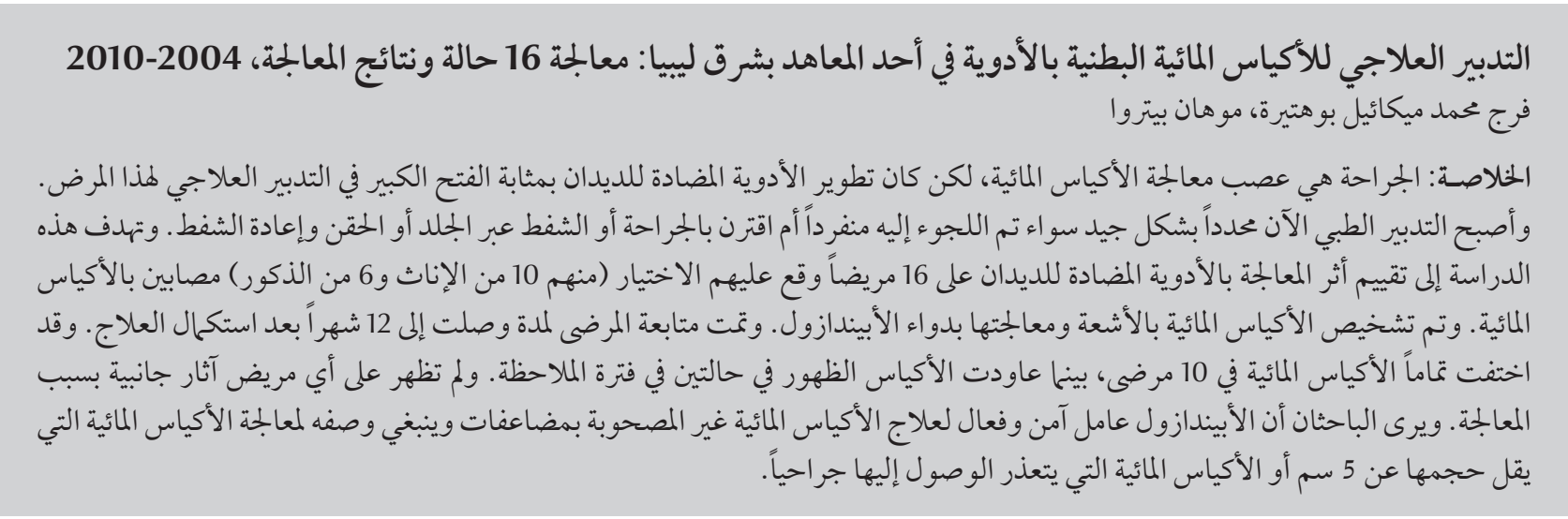

ABSTRACT Surgery is the mainstay of treatment for hydatid cyst, but the development of antihelminths has become a boon in the management of the disease. The role of medical management is now well defined, alone or with surgery or percutaneous aspiration, injection and re-aspiration (PAIR). The aim of this study was to evaluate the effect of antihelminth treatment on 16 selected patients (10 females and 6 males) with hydatid cyst. Hydatid cyst was diagnosed radiologically and treated with albendazole. Patients were followed up for 12 months after completion of therapy. Hydatid cyst collapsed completely in 10 patients; recurrence of cyst during the observation period was recorded in 2 patients. No patient in this study developed side-effects from the treatment. We suggest that albendazole is a safe and effective agent for uncomplicated hydatid cyst and should be advised for any hydatid cyst $<5 \mathrm{~cm}$ or for surgically inaccessible hydatid cyst.

Prise en charge médicamenteuse du kyste hydatique abdominal dans un hôpital de Libye orientale : traitement et résultats thérapeutiques chez 16 cas, 2004-2010

RÉSUMÉ La chirurgie est généralement la base de la prise en charge du kyste hydatique, mais la mise au point d'anthelminthiques a renouvelé I'arsenal thérapeutique dont on disposait. Le rôle du traitement médicamenteux est aujourd'hui bien défini, qu'il soit prescrit seul ou en adjuvant de la chirurgie ou du traitement percutané (PAIR : ponction, aspiration, injection, ré-aspiration). L'étude avait pour but d'évaluer l'effet du traitement anthelminthique sur 16 patients sélectionnés (10 femmes et 6 hommes) qui présentaient un kyste hydatique, ayant fait l'objet d'un diagnostic radiographique et d'un traitement à l'albendazole. Les patients ont été suivis pendant 12 mois après la fin du traitement. Le kyste hydatique a complètement disparu chez 10 patients et une récidive du kyste a été enregistrée pendant la période d'observation chez deux patients. Le traitement médicamenteux n'a entraîné aucun effet indésirable sur les patients de l'étude. Nous avançons l'idée que l'albendazole est un anthelminthique sûr et efficace en cas de kyste hydatique non compliqué et que cette option thérapeutique devrait être conseillée si la taille du kyste est inférieure à $5 \mathrm{~cm}$ ou s'il est inaccessible à la chirurgie. 


\section{Introduction}

Hydatid disease is a zoonotic infection caused by Echinococcus granulosus and Echinococcus multilocularis, which probably account for more than $95 \%$ of the estimated annual 2-3 million cases globally $[1]$.

Echinococcus has worldwide distribution. Hydatid disease is endemic in the Mediterranean area [2,3]. Although few epidemiological studies have been reported in Libya, the reported prevalence of the disease is $2 \%$ [4], and many undocumented cases are diagnosed and treated in this country [5].

The liver (70\%-80\%) and lungs $(15 \%-25 \%)$ are the most frequent locations for echinococcal cysts. Liver hydatidosis is one of the most common causes of acute abdomen in areas where the parasite is endemic. Echinococcal infestation should be suspected in patients who present with an abdominal mass, pain, fever, jaundice or anaphylaxis. However, in nonendemic areas, most cases are asymptomatic and are detected by chance $[6,7]$. Hydatid cyst may develop complications such as infection or may rupture to adjacent organs or to an anatomical cavity; anaphylaxis is the most serious complication [8]. Surgery is the treatment of choice [9], but in some instances, e.g. in small cysts or deeply seated cysts, where surgery is not feasible, only medical treatment is advocated.

Hence, the aim of this study was to evaluate the effect of antihelminths (albendazole) on hydatid cyst as an alternative treatment for surgery.

\section{Methods}

This prospective study included $16 \mathrm{pa}-$ tients, with liver cyst. They were treated in the outpatient clinic at the Department of Surgery, El Thoura Teaching Hospital, El-Beida, Libya. The study was carried out during the 6-year period 2004-2010. These 16 patients were treated exclusively with medication. During the same period 85 other cases of hydatid cyst were treated surgically or with surgical treatment followed by medical treatment. Another 3 patients refused to participate and went to other facilities.

Inclusion criteria were: hydatid cysts $<5 \mathrm{~cm}$, surgically inaccessible hydatid cyst, uncomplicated hydatid cyst. Exclusion criteria were: complicated hydatid cysts, bigger cysts, surgically accessible cysts.

We collected data from the records on patient characteristics, complaints, clinical examinations, laboratory investigations [complete blood count (eosinophil count), liver function test, renal function test, serological test (enzyme linked immunosorbent assays), Casoni's skin test] and imaging techniques [plain X-ray, abdominal ultrasound scan and computed tomography (CT) scan].

Albendazole was prescribed over courses lasting 21 days with an interval of 7 days between courses. Treatment was given over periods of 6-12 months. Dosage was $400 \mathrm{mg} \times 2$ per day except for the 1 child in the study group, who was prescribed $200 \mathrm{mg} \times 2$ per day. The abdominal ultrasound scan and liver function test were repeated monthly, during the interval period to evaluate the progress of the disease, specifically to evaluate the extent of regression of the cyst following treatment and to ident tify any recurrence. The observation and follow-up period was 12 months after completion of treatment.

\section{Results}

The study sample comprised $16 \mathrm{pa}$ tients ( 10 females and 6 males, ratio 1.7:1), with ages ranging from 9 years to 56 years [mean 33.4 standard deviation (SD) 9.0 years). Seven (7) of the patients were asymptomatic and hydatid cyst was only discovered accidentally by abdominal ultrasound scan. These patients had been scheduled ultrasound scan for a variety of reasons, such as recurrent urinary tract infection, haematuria, dyspepsia and flatulence, to exclude urinary stones or other urogenital disease and gall stones. Abdominal pain was recorded in 5 patients, infected cyst in 2 and palpable liver in 2 (Table 1). Eosinophilia $>5 \%$ was found in $6 \mathrm{pa}-$ tients. Enzyme-linked immunosorbent assay (ELISA) (Echinococcus ELISA kit, Diagnostic Automation/Cortez Diagnostics, California) was carried out for 5 patients only: 3 of these tested positive. Casoni's skin test was positive in 1 of the 2 patients tested. An abdominal ultrasound scan was carried out for all the patients by 1 expert ultrasonologist: 14 were diagnosed with hydatid cyst of the liver, with size varying from $3.0 \mathrm{~cm}$ to $5.5 \mathrm{~cm}$ at the time of examination. Only 9 patients underwent a CT scan: hydatid cyst was confirmed in all of these.

In this series, the ultrasound scan had a sensitivity of $87.5 \%$. The CT scan yielded better information: it was performed on 9 patients and was 100\% diagnostic.

Courses of albendazole were given over a period of 12 months. In 7 patients the cyst collapsed completely within the first 6 months and in 3 patients after 9 months. Albendazole failed for treatment of hydatid cyst in the remaining 6 patients.

No patient in this series reported developing any side-effects of the albendazole treatment. Recurrence of hydatid cyst was encountered in 2 patients, 12 months after completion of treatment, during the observation period.

\section{Discussion}

Cystic echinococcus is rarely fatal: occasionally deaths occur because of anaphylactic shock or cardiac tamponade in heart echinococcus cyst. Diagnosis is established and confirmed by eosinophilia and radio-imaging studies complemented with serological tests [10-13]. In our study 7 patients were asymptomatic and upper abdominal pain was found in only 5 of the cases. 
Casoni's intradermal test was the main diagnostic tool for hydatid cyst in the past, but it is now abandoned because of its low diagnostic value [14]. In our study, 1 of 2 patients tested had positive Casoni's test. ELISA was selectively used in our patients with $60 \%$ positive results.

Various imaging techniques may be used to detect hepatic hydatid cysts. Imaging techniques included plain X-ray, ultrasound scan and CT scan [15]. Plain X-ray may show a rounded calcified lesion in the film $[14,16]$. Ultrasound scan and CT scan will reveal the morphological characteristic of the cyst and the exact position $[17-19]$.

Preoperative courses of albendazole have been used to sterilize the cyst, decrease the chance of anaphylaxis, decrease the tension in the cyst wall (thus reducing the risk of spillage during surgery), and reduce the recurrence rate postoperatively [9]. Albendazole has been shown to be significantly more effective than mebendazole in the treatment of liver hydatidosis and benzimidazole treatment alone requires prolonged administration over many weeks, with an unpredictable outcome in terms of response rates in individuals [20,21].

A number of researchers have reported that these agents can achieve subjective improvement, by killing the scolices and decreasing secretion of hydatid fluid, thereby inducing shrinkage of the cyst $[22,23]$. The cyst is replaced by new granulation of tissue (regeneration) within a few months to a few years [24]. In our study, 10 of the 16 patients responded to treatment with complete cystic collapse within 6-12 months. Similar findings were reported

\begin{tabular}{|c|c|}
\hline Characteristic & No. \\
\hline \multicolumn{2}{|l|}{ Sex } \\
\hline Female & 10 \\
\hline Male & 6 \\
\hline \multicolumn{2}{|l|}{ Clinical features } \\
\hline Asymptomatic & 7 \\
\hline Upper abdominal pain & 5 \\
\hline Vomiting & 3 \\
\hline Jaundice & 1 \\
\hline Fever & 2 \\
\hline Palapable mass & 2 \\
\hline \multicolumn{2}{|l|}{ Investigations } \\
\hline Eosinophilia $(>5 \%)$ & 6 \\
\hline +ve ELISA $(n=5)$ & 3 \\
\hline +ve Casoni's test $(n=2)$ & 1 \\
\hline \multicolumn{2}{|l|}{ Imaging techniques } \\
\hline Plain X-ray of abdomen (calcified lesion ) & 0 \\
\hline Abdominal ultrasound scan (hydatid cyst) & 14 \\
\hline Abdominal CT scan (hydatid cyst) $(n=9)$ & 9 \\
\hline
\end{tabular}

No. of patients $=16$ except where indicated .

$E L I S A=$ enzyme-linked immunosorbent assay; $C T=$ computed tomography.

in a previous study on 40 patients in Libya [23].

The recurrence rate in our patients was $20 \%$. Filippou et al. and De reported a recurrence rate of $2 \%$ and a survival rate of $95 \%$ in patients undergoing operative intervention. Albendazole, as sole medical therapy, has resulted in successful treatment in up to $40 \%$ of cases $[21,25]$.

It has been reported that antihelminthic agents may cause hepatotoxicity, nephrotoxicity or haemolytic disorders [26]. These side-effects were not recorded in our patients in this study, nor in a previous study conducted in Libya by El Mufti [23].

\section{Conclusion}

Surgery is the mainstay of management of abdominal hydatid cyst. But medical management is effective and comparatively safe treatment, especially for small, deep inaccessible lesions and for the patients who are either unfit for surgery or refused to have surgery. In addition, it is an adjuvant treatment along with surgery or percutaneous aspiration, injection and re-aspiration (PAIR).

Funding: This study was self funded; but the investigations were carried out free in the hospital and drugs were delivered free to the patients.

Competing interests: None declared.

\section{References}

1. Gorad K et al. Laparoscopic removal of pelvic hydatid cysts in young female: A case report. Minimally Invasive Surgery, 2011, 346828.

2. Cuschieri A, Giles GR, Mossa AR. Parasitic infestations of surgical importance: Hydatid disease. In: Cuschieri A et al., eds. Essential Surgical Practice. Oxford, Butterworth-Heinemann, 1995:243-246.
3. Russell RCG, William NS, Bulstrode CJR, eds. (Parasitic infections : cystic hydatid disease In: Baily \& Love's Short practice of surgery, 24th ed. London, Hodder Arnod UK, 2004:165-169.

4. Elburjo M, Gani EA. Surgical management of pulmonary hydatid cyst in children. Al-Arab Medical University, Benghazi, Libya. Thorax, 1995, 50:396-398. 
5. Fadel MD, Farag M, Makael MD. Surgical procedures for abdominal hydatidcyst: a mini review. Benha Medical Journal, 2009, 26:257-264

6. Beecher EE et al. (2000): Cystic diseases of the liver. In: Zuidema GD, Yeo CJ, eds. Shackelford's surgery of the alimentary tract, 5th ed.,vol III. Philadelphia, WB Saunders Company, 452-460.

7. Huizinga WKJ, Grant CS, Darr AS. Hydatid disease. In: Morris PJ, Wood WC, eds. Oxford textbook of surgery, 2nd ed. Oxford, Oxford University Press, 2000:3298-3305.

8. Saenz de San Pedro B et al. Anaphylactic shock by rupture of hydatid hepatic cyst. Follow-up by specific IgE serum antibodies. Allergy, 1992, 47:568-570.

9. Gourgiotis $S$ et al. Surgical techniques and treatment for hepatic hydatid cysts. Surgery Today, 2007, 37:389-395.

10. Singh RK. A case of disseminated abdominal hydatidosis. Journal of the Association of Physicians of India, 2008, 56:55.

11. Lim $\mathrm{JH}$. Parasitic diseases in the abdomen: imaging findings. Abdominal Imaging, 2008, 33:130-132.

12. Yang YR et al. Serological prevalence of echinococcosis and risk factors for infection among children in rural communities of southern Ningxia, China. Tropical Medicine \& International Health, 2008, 13:1086-1094.

13. Ilical AT et al. Extrahepatic abdominal hydatid disease caused by echinococcus granulosus: Imaging findings. American Journal of Roentgenology, 2007, 189(2):337-343.

14. Ref LangerJC et al. Diagnosis and management of hydatid disa ease of the liver. A 15-year North American experience. Annals of Surgery, 1984, 199(4): 412-417.

15. Clements R, Gravelle IH. Radiological appearances of hydatid disease in Wales. Postgraduate Medical Journal, 1986, 62(725):167-173.
16. Langer B. Surgical treatment of hydatid disease of the liver. British Journal of Surgery, 1987, 774(4):237-238.

17. Papadimetrian J, Mandrekas A. The surgical treatment of hydatid disease of the liver. British Journal of Surgery, 1970, 57(6):431-433.

18. Al-Hashimi H.M. Intrabiliary rupture of the hydatid cyst of the liver. British Journal of Surgery, 1971, 58(3):228-232.

19. Sayek I, Yalin R, Sana CY. Surgical treatment of hydatid disease of the liver. Archives of Surgery, 1980, 115(7):847-850.

20. Stojkovic $M$ et al. Treatment response of cystic echinococcus. Chinese Medical Journal, 2000, 113:827-832.

21. Filippou D et al. Advances in liver echinococcosis: diagnosis and treatment. Clinical Gastroenterology and Hepatology, 2007, 5:152-159.

22. Safioleas M et al. Surgical treatment of human echinococcosis. International Surgery, 2000, 85:358-365.

23. El-Mufti $M$ et al. Albendazole therapy of hydatid disease: 2-year follow-up of 40 cases. Annals of Tropical Medicine and Parasitology, 1993, 87:241-246.

24. Lin TY et al. Regeneration of human liver after hepatic lobectomy studied by repeated liver scanning and repeated needle biopsy. Annals of surgery, 1979, 190:48-53.

25. De U. Primary abdominal hydatid cyst presenting in emergency as appendicular mass: a case report. World Journal of Emergency Surgery, 2009, 4:13.

26. Cunha P (ed). RxList, the Internet Drug Index: Albenza. California, WebMD 2013 (http://www.rxlist.com/albenza-drug/ indications-dosage.htm, accessed 2 June 2013). 